\title{
University of the Free State medical students' view of at-risk drinking behaviour and psychoactive substance use
}

P Smit, MB ChB, MMed (Psych)

P J Pretorius, MB ChB, MMed (Psych)

Department of Psychiatry, Faculty of Health Sciences, University of the Free State, Bloemfontein

\section{G Joubert, BA, MSC}

Department of Biostatistics, Faculty of Health Sciences, University of the Free State

Objectives. To investigate undergraduate medical students' knowledge of at-risk drinking behaviour and their own patterns of alcohol intake. The use of non-alcoholic psychoactive substances was also investigated.

Design. A cross-sectional study design was used. Participants completed a self-administered anonymous questionnaire designed using the US Department of Health and Human Services guidelines for identifying at-risk drinking.

Setting. The School of Medicine, University of the Free State, Bloemfontein

Subjects. Participants included first-, fourth- and fifth-yea medical students enrolled in 2006

Results. Of 408 questionnaires, 371 (90.9\%) were returned. Of students who repeated an academic year, 10\% ascribed it to substance use. The majority of students conservatively estimated the maximum daily and weekly safe levels of alcohol consumption for both men and women as notably lower than set by the guidelines. Nevertheless, $32 \%$ of students admitted to alcohol intake exceeding these limits, and $55.3 \%$ were identified as at-risk drinkers. Marijuana was the most common non-alcoholic substance used by medical students $(14.6 \%)$ in the preceding 3 years. Alcohol and other substances were most frequently used during social activities with friends.

Conclusions. Both medical students' knowledge of levels of alcohol intake associated with increased risks and their own drinking patterns could potentially influence their approach to patients with alcohol-related problems. Education regarding at-risk drinking behaviour therefore needs to be addressed.

Students undertaking a career in medicine are generally high achievers and are expected to demonstrate the capacity to adapt to both academic and time demands and the responsibility of dealing with patients. It is often assumed that they will remain functional and unimpaired through employing effective coping mechanisms, but the reality is that they are not always prepared for this challenge.

Maladaptive coping skills may develop during a doctor's training and continue throughout his or her professional life. This could have adverse consequences for themselves, their families and their patients.' One of these maladaptive responses can be the use or abuse of substances.

There are three main reasons why substance abuse among medical students is of particular concern. ${ }^{2}$ Firstly, as clinicians they will treat patients with substance-related problems and complications, and their own attitudes towards substance use may influence professional advice and patient management. Secondly, the reported high prevalence of alcohol and drug problems among physicians ${ }^{3}$ may stem from substance use patterns established during undergraduate training. Thirdly, students' academic performance may be negatively influenced by high alcohol consumption and other substance use.

Medical students' view of what constitutes at-risk drinking behaviour is likely to influence not only their own alcohol intake but also their management of patients with risky drinking patterns. The US Department of Health and Human Services guidelines on diagnosing at-risk drinking behaviour ${ }^{4}$ were used for the purpose of this study. Persons exceeding the limits set out in these guidelines are at increased risk of alcohol-related problems such as hypertension, gastrointestinal bleeding, sleep disorders, major depression, haemorrhagic stroke, cirrhosis of the liver and several forms of cancer. ${ }^{5}$ Individual susceptibility to alcohol-related complications varies and lower levels of intake may be advised depending on factors such as age, coexisting medical conditions and medication use.

Clinicians are in a position to influence substance use behaviour in their patients directly or indirectly through early identification and interventions as well as by setting an example. ${ }^{6}$ Research has demonstrated the possibility that brief interventions may promote significant and lasting reductions of alcohol intake in patients with at-risk drinking patterns. ${ }^{7}$ Repeated alcohol-focused contacts with a health provider can lead to significant improvement in at-risk behaviour, even in patients who do not accept referral for formal rehabilitation. ${ }^{8,9}$ It is therefore important to become aware of 
medical students' knowledge and perceptions of at-risk drinking behaviour, and it is of paramount importance that students be educated in this field.

The aims of this study were twofold. We hoped to establish whether undergraduate medical students at the University of the Free State (UFS) have knowledge of current concepts of at-risk drinking behaviour, and further to establish the patterns of alcohol intake of the medical students who participated. The study further looked at gender differences in students' knowledge of at-risk drinking. At-risk drinking patterns as well as prevalence of alcohol abuse and alcohol dependence were determined. The type and pattern of non-alcoholic psychoactive substance use were also investigated. Drug-taking situations and possible triggers preceding episodes of substance use were compared between junior and senior as well as between male and female students.

\section{Methods}

A cross-sectional study design was used. The study population consisted of all first-, fourth- and fifth-year medical students enrolled at the UFS during 2006. This study population was chosen to establish whether differences in substance use patterns among junior (first-year) and senior (fourth-and fifth-year) students exist lit was convenient to include both the senior classes because they attended the same compulsory lectures).

Students were informed that participation was voluntary and that information would be kept strictly confidential. They were also made aware that participation was anonymous and that information gathered could not be linked to a specific participant. The purpose of the study was explained and the students were given an opportunity to ask questions before a self-administered questionnaire was handed to them. The questionnaire was based on the US Department of Health and Human Services guidelines for identification of at-risk drinking behaviour ${ }^{4}$ and included biographical data, types and frequency of substances used, and situations in which substances were used during the past year.

At-risk drinking in males was defined as more than 14 standard drinks per week, or more than 4 standard drinks per day, at any time during the past year. For females it was defined as more than 7 standard drinks per week, or more than 3 standard drinks per day, at any time during the past year. ${ }^{4}$

Non-alcoholic psychoactive substances were defined according to the classes in the Mini International Neuropsychiatric Interview (MINI, English version 5.0.0). ${ }^{10}$ These substances included stimulants, cocaine, narcotics, hallucinogens, inhalants, marijuana, tranquillisers and miscellaneous substances. In each class, examples and street names were provided and students were requested to report if they had used any of the substances during the past 3 years and during the past year. The Inventory of Drug Taking Situations (IDTS)" was used to measure the degree to which individual students used substances in different situations over the past year.

The study was approved by the Ethics Committee of the Faculty of Health Sciences at the UFS. Consent was also obtained from the Vice-Rector: Academic Planning, the Head of the School of Medicine and the Dean of Student Services. A pilot study was conducted among five doctors in their internship year to obtain feedback regarding the questionnaires before proceeding with the study. The Department of Biostatistics at the UFS performed the statistical analysis. Frequencies and percentages were used to summarise results and subgroup comparisons were done using $95 \%$ confidence intervals for differences in percentages. Fisher's exact tests or chi-square tests were used where applicable.

\section{Results}

Of a total of 408 questionnaires handed out, 371 were completed (response rate 90.9\%). Demographic data on the respondents are summarised in Table I. Approximately $11 \%$ of respondents had failed an academic year. Equal numbers of respondents (10.5\% in each group) were either sure or uncertain that substance use had contributed to their failure.

The respondents' views of what constitutes at-risk drinking are summarised in Fig. 1. It is noteworthy that the majority of students' estimates of both weekly and daily limits for safe drinking were much lower than the limits set by the US Department of Health and Human Services. ${ }^{4}$ Approximately $83 \%$ of all students (both genders) regarded safe daily and weekly limits for men as being far lower than the accepted limits. Similarly, limits for women were estimated as lower than the accepted limits by $83 \%$ of respondents for daily and $91 \%$ for weekly numbers of drinks. Only $2.6 \%$ of students correctly identified the daily limits for men and $1.6 \%$ those for women. Students were somewhat more accurate in estimating the correct weekly limit for women (8.1\%) than for men (1.3\%).

Students' own alcohol use during the preceding year is summarised in Table II. Fiffy-five per cent of participants fulfilled criteria for at risk drinking according to the US Department of Health and Human Services Guidelines, with 31.8\% exceeding both weekly and daily limits; $23 \%$ and $0.8 \%$, respectively, exceeded only the daily or weekly limits. As expected, at-risk drinking behaviour 


\begin{tabular}{|c|c|c|c|}
\hline \multirow[b]{2}{*}{ Variable } & \multicolumn{2}{|c|}{ Student group } & \multirow[b]{2}{*}{$\begin{array}{l}\text { Total } \\
(\mathrm{N}=371)\end{array}$} \\
\hline & $\begin{array}{l}\text { Junior } \\
\text { (1st year) } \\
(\mathrm{N}=147)\end{array}$ & $\begin{array}{l}\text { Senior (4th } \\
\& 5 \text { th year) } \\
(N=224)\end{array}$ & \\
\hline \multicolumn{4}{|l|}{ Age (yrs) } \\
\hline $18-19$ & 66.6 & 0.4 & 26.3 \\
\hline $20-24$ & 29.9 & 79.0 & 59.6 \\
\hline $25-29$ & 2.0 & 18.8 & 12.1 \\
\hline $30-34$ & 0.0 & 1.3 & 0.8 \\
\hline$>34$ & 1.4 & 0.4 & 0.8 \\
\hline \multicolumn{4}{|l|}{ Gender } \\
\hline Male & 49.0 & 48.7 & 48.8 \\
\hline Female & 51.0 & 51.3 & 51.2 \\
\hline \multicolumn{4}{|c|}{ Class attended } \\
\hline Afrikaans & 49.7 & 50.9 & 50.4 \\
\hline English & 50.3 & 49.1 & 49.6 \\
\hline \multicolumn{4}{|c|}{$\begin{array}{l}\text { Current academic } \\
\text { year }\end{array}$} \\
\hline MB ChB I & 100 & & 39.6 \\
\hline MB ChB IV & & 52.2 & \multirow{2}{*}{60.4} \\
\hline MB ChB V & & 47.8 & \\
\hline \multicolumn{4}{|l|}{ Marital status } \\
\hline Married & 1.4 & 5.3 & 3.8 \\
\hline Single & 98.6 & 94.2 & 96.0 \\
\hline Divorced & 0 & 0.4 & 0.3 \\
\hline \multicolumn{4}{|c|}{$\begin{array}{l}\text { Have you ever } \\
\text { repeated a year of } \\
\text { your studies? }\end{array}$} \\
\hline Yes & 8.2 & 12.1 & 10.5 \\
\hline \multicolumn{4}{|c|}{$\begin{array}{l}\text { If yes, do you } \\
\text { think substances } \\
\text { contributed to you } \\
\text { failing a year? }\end{array}$} \\
\hline Yes & 8.3 & 11.5 & 10.5 \\
\hline No & 75.0 & 80.8 & 79.0 \\
\hline Unsure & 16.7 & 7.7 & 10.5 \\
\hline
\end{tabular}

was much less common among female students than among males $(45.3 \%$ v. $65.8 \%$; $95 \%$ confidence interval $(\mathrm{Cl})-30.0 \%$ to $-0.4 \%)$. Contrary to expectations, senior students had a notably higher percentage of at-risk drinking in comparison with junior students (58\% v. $51 \%$, respectively; $95 \% \mathrm{Cl}-3 \%$ to $17.2 \%$ ).

Students' self-reported behavioural, physical, psychological and social sequelae of alcohol use, as selected from a checklist provided by the authors, are summarised in Table III. The checklist was based on DSM-IV criteria for alcohol abuse and dependence. ${ }^{12}$

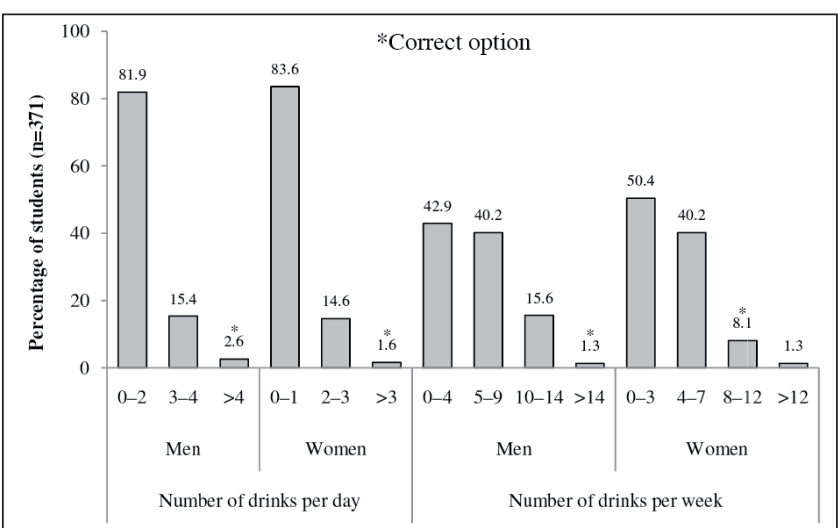

Fig. 1. Students' views of what they regarded as the daily and weekly maximum limits for safe drinking for men and women. *US Department of Health and Human Services Guidelines: at-risk drinking in males $=>4$ standard drinks/day or $>14$ standard drinks/week, at any time during the past year; at-risk drinking in females $=>3$ standard drinks/day or $>7$ standard drinks/week at any time during the past year. ${ }^{4}$

A considerable percentage $(29.9 \%)$ of students indicated that they often drove while drinking or after having had too much to drink. Forty-seven per cent reported drinking more than they intended to or often continued drinking for longer than they had initially intended to.

The results for non-alcoholic substance use are summarised in Table IV. Information about non-alcoholic substance use was obtained for the past 1 and the past 3 years. It is noteworthy that senior students had higher rates of use of all substances on all parameters. Eight per cent of the study population had used miscellaneous substances during the past 3 years, which included over-the-counter non-prescription sedatives and diet pills.

The results of the Inventory of Drug Taking Situations (IDTS) are summarised in Table $V$. The majority of students who used substances did so in social situations. It therefore seems that social factors play a major role in students' drinking behaviour. Senior students used substances significantly more frequently in social situations (Table V, items 6,7 and $11 ; p=0.05,0.01$ and 0.03 , respectively). The subgroup of students who reported use of substances in response to emotional factors is of concern. These circumstances included feeling depressed $(6.7 \%$ frequently), feeling that they had let themselves down (5.4\% frequently), or when anxious or tense $15.1 \%$ frequently). Junior students were significantly more likely than senior students to choose 'never' for items 2, 3, 5 and $9(p=0.03,0.01,0.01$ and 0.01 , respectively) (Table V).

\section{Discussion}

The medical students in our study had poor knowledge of the levels of alcohol consumption that may be associated with an 
Table II. Students' alcohol use in the preceding year according to criteria for at-risk drinking (\%)

\begin{tabular}{|c|c|c|c|c|c|}
\hline \multirow[b]{2}{*}{ Drinking behaviour } & \multicolumn{5}{|c|}{ Student group } \\
\hline & $\begin{array}{l}\text { Junior } \\
(N=147)\end{array}$ & $\begin{array}{l}\text { Senior } \\
(N=224)\end{array}$ & $\begin{array}{l}\text { Male } \\
(N=181)\end{array}$ & $\begin{array}{l}\text { Female } \\
(N=190)\end{array}$ & $\begin{array}{l}\text { Total } \\
(N=371)\end{array}$ \\
\hline Never exceeded daily or weekly limit & 49 & 42 & 34.3 & 54.7 & 44.7 \\
\hline Only exceeded daily limit (binges) & 23.8 & 21.9 & 26 & 19.5 & 22.6 \\
\hline Only exceeded weekly limit & 1.4 & 0.5 & 1.1 & 0.5 & 0.8 \\
\hline Exceeded both daily and weekly limit & 25.9 & 35.7 & 38.7 & 25.3 & 31.8 \\
\hline $\begin{array}{l}\text { At-risk drinkers: exceeded either weekly or } \\
\text { daily limits, or both }\end{array}$ & 51 & 58 & 65.8 & 45.3 & 55.3 \\
\hline
\end{tabular}

Table III. Students' self-reported behavioural, physical,

psychological and social sequelae of alcohol use, based on DSM-IV criteria for alcohol abuse and dependence ${ }^{12}$

\begin{tabular}{ll}
\hline Sequelae & $\%$ \\
\hline Inability to cut down or stop & 47.7 \\
Risk of bodily harm & 29.9 \\
Tolerance to alcohol & 18.3 \\
Spending less time on other matters & 16.4 \\
Signs of withdrawal & 11.9 \\
Role failure & 10.8 \\
Interpersonal problems & 8.9 \\
Continue drinking despite physical or & 8.4 \\
psychological complications & 7.3 \\
Inability to stick to drinking limits & 4.0 \\
Spending a lot of time drinking & 3.5 \\
Altercation with the law &
\end{tabular}

increased risk of development of long-term medical and psychiatric complications. Students' level of seniority did not improve their knowledge of criteria for at-risk drinking. It is of concern that students' personal substance use patterns were not influenced by their overly conservative estimates of limits for safe drinking; 55\% fulfilled criteria for levels of alcohol intake that placed them at increased risk for development of long-term problems.

No similar studies using the US Department of Health and Human Services 2005 criteria $^{4}$ for at-risk drinking could be found in the literature. Previous studies among medical students used varying criteria for at-risk drinking with reported ranges of between $28 \%$ and $51 \% .^{13-15}$ Most of these studies, however, used less stringent criteria than those used in our research. Despite similarities in the percentages of at-risk drinking, direct comparisons between our study and others reported in the literature are therefore not possible.

Table IV. Students using non-alcoholic substances in the past year or 3 years (\%)

\begin{tabular}{|c|c|c|c|c|c|c|c|c|c|}
\hline \multirow[b]{2}{*}{ Substance } & \multicolumn{3}{|c|}{ Used in the past 3 years } & \multicolumn{3}{|c|}{ Used in the past year } & \multicolumn{3}{|c|}{$\begin{array}{c}\text { Used more than once in the } \\
\text { past year }\end{array}$} \\
\hline & $\begin{array}{l}\text { Junior } \\
(N=147)\end{array}$ & $\begin{array}{l}\text { Senior } \\
(N=224)\end{array}$ & $\begin{array}{c}\text { Total } \\
(N=371)\end{array}$ & $\begin{array}{l}\text { Junior } \\
(N=147)\end{array}$ & $\begin{array}{l}\text { Senior } \\
(N=224)\end{array}$ & $\begin{array}{c}\text { Total } \\
(N=371)\end{array}$ & $\begin{array}{l}\text { Junior } \\
(N=147)\end{array}$ & $\begin{array}{l}\text { Senior } \\
(N=224)\end{array}$ & $\begin{array}{c}\text { Total } \\
(N=371)\end{array}$ \\
\hline Stimulants & 3.4 & 7.1 & 5.7 & 1.4 & 4.5 & 3.2 & 0 & 3.1 & 1.9 \\
\hline Narcotics & 0.7 & 5.8 & 3.8 & 0 & 4 & 2.4 & 0 & 3.1 & 1.9 \\
\hline Hallucinogens & 0.7 & 1.8 & 1.4 & 0 & 1.3 & 0.8 & 0 & 0 & 0 \\
\hline Inhalants & 0 & 0.5 & 0.3 & 0 & 0.5 & 0.3 & 0 & 0 & 0 \\
\hline Marijuana & 12.9 & 15.6 & 14.6 & 8.8 & 8.5 & 8.6 & 2 & 3.1 & 2.7 \\
\hline Tranquillisers & 3.4 & 2.7 & 3 & 2.7 & 2.2 & 2.4 & 2.7 & 1.3 & 1.9 \\
\hline
\end{tabular}


Table V. Inventory of alcohol- and drug-taking situations (\%)

\begin{tabular}{|c|c|c|c|c|}
\hline \multirow[b]{2}{*}{ Situation } & \multicolumn{4}{|c|}{ Response } \\
\hline & Never & Rarely & Frequently & $\begin{array}{l}\text { Almost } \\
\text { always }\end{array}$ \\
\hline 1. When I was depressed about things in general & 65.8 & 27 & 6.7 & 0.5 \\
\hline $\begin{array}{l}\text { 2. When I felt tense or uneasy in the presence of } \\
\text { someone }\end{array}$ & 71.7 & 20 & 7.6 & 0.8 \\
\hline 3. When I had let myself down & 79.5 & 14.6 & 5.4 & 0.3 \\
\hline $\begin{array}{l}\text { 4. When other people rejected me or did not } \\
\text { seem to like me }\end{array}$ & 90.2 & 8.1 & 0.8 & 0.8 \\
\hline 5. When I felt anxious or tense about something & 72.7 & 22.1 & 5.1 & 0.5 \\
\hline $\begin{array}{l}\text { 6. When I was with friends or wanted to increase } \\
\text { enjoyment }\end{array}$ & 38 & 26.7 & 26.1 & 9.2 \\
\hline 7. When I wanted to celebrate with a friend & 28.6 & 28.3 & 29.1 & 14 \\
\hline 8. When I felt confused about what I should do & 85.2 & 11.6 & 2.2 & 1.1 \\
\hline 9. When I was lonely & 87.6 & 10 & 1.9 & 0.5 \\
\hline $\begin{array}{l}\text { 10. When I felt that my family was putting a lot of } \\
\text { pressure on me or that I did not measure up to } \\
\text { their expectations }\end{array}$ & 90 & 7.8 & 1.9 & 0.3 \\
\hline $\begin{array}{l}\text { 11. When I was with a group of friends and } \\
\text { everyone was drinking }\end{array}$ & 39.6 & 27 & 21.3 & 12.1 \\
\hline 12. When I felt there was nowhere left to turn & 92.7 & 5.4 & 0.8 & 1.1 \\
\hline
\end{tabular}

Ashton et al. ${ }^{13}$ reported the prevalence of at-risk drinking in male and female medical students to be $32 \%$ and $21 \%$, respectively. According to a study conducted by Newbury-Birch et al. ${ }^{14} 45 \%$ of first-year medical students exceeded the recommended limits for alcohol consumption. In comparison, 51\% of our junior study population fulfilled the more stringent US Department of Health and Human Services criteria for at-risk drinking. ${ }^{10}$

Pickard et al. ${ }^{15}$ found that $51 \%$ of second-year medical students at a university in the UK exceeded the recommended safe limits of alcohol consumption. A study conducted at the University of the Free State during 2001 found that $28 \%$ of 6th-year medical students used alcohol in a harmful way. ${ }^{16}$ However, the selfrated Alcohol Use Disorder Identification Test (AUDIT) was used as measuring instrument in that study. ${ }^{17}$ The difference in results between our recent study and the 2001 one might be explained by the new and more stringent criteria for at-risk alcohol use. ${ }^{4}$

Marijuana was the most frequently used non-alcoholic substance, but fewer students had used cannabis in the past year than in the past 3 years. This indicated discontinuation of cannabis use in some students as their studies progressed. The general frequency of use of non-alcoholic substances seems to be low. Substances in the miscellaneous group were the most frequently used.

Results from this study must be viewed in light of the limitations of the self-reporting measurement instruments used, which include recall bias, reporting errors, and non-response bias. A cross-sectional study reveals a 'snapshot in time', and without longitudinal samples we cannot comment whether these results are generally stable or vary over time in this population. This study involved a relatively small sample from one medical school and results can therefore not be generalised. The possible role of increased academic and time demands and the responsibility of dealing with patients have been identified as important factors contributing to increased use of substances by previous authors.

Our study did not sufficiently investigate factors that contribute to increased substance use among senior students. However, social factors seem to be an important factor influencing students' drinking behaviour. Of more concern is the group of students who use substances as a method of coping with stress, as well as those who use illegal and highly addictive substances to which they may be exposed while practising their future occupation. 
Research needs to focus on identifying a possible subgroup of students who may be at particular risk for developing more persistent ineffective stress coping strategies.

This study highlights the poor knowledge of criteria for at-risk drinking among future clinicians. It should alert medical schools to the lack of sufficient training about potentially damaging levels of substance use. In a recent study of primary care practices, only $10 \%$ of patients with alcohol dependence received the recommended quality of care, including assessment and referral for treatment. ${ }^{18}$ The percentage of students who are assessed and referred for treatment is probably even lower. The insidious onset and chronicity of substance abuse among physicians point to a need for further studies to identify a possible subgroup of students at increased risk for sustained excessive substance use after completion of their studies. Our study also demonstrated a relatively high prevalence of substance use among senior medical students. A similar finding was made in a study of medical students in India. ${ }^{19}$ It seems that social rather than stress-related factors contributed to this increase.

\section{Conclusion}

From the results of this study it is clear that more than half (55.3\%) of medical students' alcohol use qualifies as atrisk drinking according to currently accepted norms. The findings of this study are relevant for planning of the undergraduate curriculum in terms of education in the field of addiction psychiatry. It is reasonable to assume that students' knowledge will influence not only their own alcohol intake but also the advice they will give to their patients regarding safe and risky drinking habits. Medical schools should make proper provision for student health care and support services, and ensure that those working in these services are properly trained in the identification and management of alcoholic and non-alcoholic substance use. Students should also be taught how to cope with stress in a healthy way and should be given the opportunity to talk to a counsellor or tutor when they experience problems. This could contribute to the prevention of substance use as a mechanism to cope with stressful situations. The results of this study could serve as baseline figures for further descriptive and intervention studies.
We thank the 2006 first-, fourth- and fifth-year medical students who participated in the study, and Daleen Struwig, medical writer, Faculty of Health Sciences, UFS, for technical and editorial preparation of the manuscript for publication.

\section{References}

1. Shapiro EC, Lowenstein LM. Becoming a Physician: Development of Values and Attitudes in Medicine. Cambridge, MA: Ballinger Publishing Company, 1979: 201 205.

2. Tyssen R, Vaglum $P$, Aaslend OG, Grenvold NT, Ekeberg $O$. Use of alcohol to cope with tension, and its relation to gender, years in medical school and hazardous drinking - a study of two nation-wide Norwegian samples of medical students. Addiction 1998; 93: 1341-1349.

3. Flaherty JA, Richman JA. Substance use and addiction among medical students, residents and physicians. Psychiatr Clin North Am 1993; 16: 189-197.

4. Department of Health and Human Services, National Institutes of Health, USA Government. Helping patients who drink too much: a clinician's guide, updated 2005 edition. http://pubs.niaaa.nih.gov/publications/Practitioner/ CliniciansGuide2005/guide.pdf (accessed 12 July 2007)

5. Rehm J, Room R, Graham K, Monteiro M, Gmel G, Sempos CT. The relationship of average volume of alcohol consumption and patterns of drinking to burden of disease: An overview. Addiction 2003; 98: $1209-1228$

6. Gray JD, Bhopal RS, White M. Developing a medical school alcohol policy. Med Educ 1998; 32: 138-142.

7. Fleming MF, Mundt MP, French MT, Manwell LB, Staauffacher EA, Barry KL. Brief physician advice for problem drinkers: Long-term efficacy and cost-benefit analysis. Alcoholism, Clinical and Experimental Research 2002; 26: 36-43

8. Willenbring ML, Olson DH. A randomized trial of integrated outpatient treatment for medically ill alcoholic men. Arch Intern Med 1999: 159: 1946-1952

9. Lieber CS, Weiss DG, Groszmann R, Paronetto F, Schenker S, for the Veterans Affairs Cooperative Study 391 Group II. Veterans Affairs cooperative study of polyenylphosphatidylcholine in alcoholic liver disease. Alcoholism, Clinical and Experimental Research 2003: 27: 1765-1772.

10. Sheehan DV, Lecubrier $Y$, Hartnett-Sheehan $K$, et al. The Mini International Neuropsychiatric Interview (MINI): the development and validation of a structured diagnostic psychiatric for DSM IV and ICD 10. J Clin Psychiatry 1998; 59: suppl. 20, 22-33.

11. Sojatovic M, Ramirez LF. Rating Scales in Mental Health. Ohio: Lexi-Comp Inc. 2001: 264-270

12. American Psychiatric Association. Diagnostic and Statistical Manual of Mental Disorders. 4th ed. Washington DC: American Psychiatric Association, 1994: 181 183.

13. Ashton $\mathrm{CH}$, Kamali F. Personality, lifestyles, alcohol and drug consumption in a sample of British medical students. Med Educ 1995; 29: 187-192.

14. Newbury-Birch D, White M, Kamali F. Factors influencing alcohol and illicit drug use amongst medical students. Drug Alcohol Depend 2000; 59: 125-130

15. Pickard $M$, Bales $L$, Donan $M$, et al. Alcohol and drug use in second year medical students at the University of Leeds. Med Educ 2000; 34: 148-150.

16. Marais AL, Calitz FJN, Rataemane LUZ, Joubert G. Alcohol use among sixth-year medical students at the University of the Free State. S Afr J Psychiatr 2002; 8: 79-84.

17. Allen JP, Colombus M. Assessing Alcohol Problems: A Guide for Clinicians and Researchers. Bethesda, MD: National Institute on Alcohol Abuse and Alcoholism, 1995: 260-262.

18. McGlynn EA, Asch $S M$, Adams J, et al. The quality of health care delivered to adults in the United States. N Engl J Med 2003; 348: 2635-2645.

19. Naskar NN, Bhattacharya SK. A study on drug abuse among the undergraduate medical students in Calcutta. J Indian Med Assoc 1999; 97: 20-21. 